\title{
PHOTOLUMINESCENCE PROPERTIES OF GD(III) AND CE(III) LANTHANIDE BASED METAL ORGANIC FRAMEWORKS
}

\author{
Yasemin ACAR* \\ Department of Physics, Faculty of Art and Science, Balıkesir University, Balıkesir, TURKEY
}

\begin{abstract}
The Gd(III) and Ce(III) based-MOFs (metal organic frameworks) have been synthesized by hydrothermal method using 1,2,4,5-benzenetetracarboxylate (btec) ligand and characterized by elemental analysis, FT-IR, UV-visible and single-crystal $\mathrm{X}$-ray diffraction. The crystal structure analysis of $\mathrm{Gd}(\mathrm{III})$ complex $\left[\mathrm{C}_{10} \mathrm{H}_{9} \mathrm{GdO}_{11}\right]$ (1) and $\mathrm{Ce}$ (III) complex $\left[\mathrm{C}_{10} \mathrm{H}_{5} \mathrm{CeO}_{9}\right](\mathbf{2})$ show that the central lanthanide ions are coordinated by nine oxygen atoms in which eight $\mathrm{O}$ atoms from btec ligands and one $\mathrm{O}$ atom from water molecule for both structures. The nearest non-bonding $\mathrm{Gd} \cdots \mathrm{Gd}$ distance is $3.928 \AA$ while $\mathrm{Ce} \cdots \mathrm{Ce}$ distance is $4.392 \AA$. Complex 1 and 2 bridged by oxygen atoms of btec ligands are formed in 3D networks via strong hydrogen bonds. Additionally, solid state photoluminescence properties of $\mathbf{1}$ and $\mathbf{2}$ at room temperature have been investigated. Under the excitation of UV light, intense cyan-blue emission for complex $\mathbf{1}$ and blue emission for complex $\mathbf{2}$ are exhibited in the visible regions.
\end{abstract}

Keywords: Metal-Organic Frameworks, Lanthanide Complexes, Structural Analysis, Photoluminescence Properties

\section{INTRODUCTION}

In recent years, the design and synthesis of metal-organic frameworks (MOFs) as functional materials have been great deal of attention not only because of their interesting topologies, but also because of their potential applications in catalysis, gas storage, sensing, magnetism, molecular adsorption and drug delivery [1-9]. MOFs are porous materials in which metal ions or clusters are linked together by organic ligands containing $\mathrm{N}$ - or O-donors into 2D or 3D networks. Although there have been numerous studies on MOFs based on transition metals, lanthanide based metal organic frameworks (LnMOFs) have been quite limited [10-11]. The use of lanthanides in MOFs as metal centers is becoming quite popular in recent years due to these cations are associated with the comprising magnetism and photoluminescence, having higher coordination numbers than transition metals, their geometries and multidimensional structures leading to 2D or 3D networks [12-17]. In addition, hydrothermal synthesis technique is the most common and accomplished method to synthesis the lanthanide based porous materials $[18,19]$. Although there have been numerous factors such as the structural characteristics of the ligands and metal ions, the presence of solvents, the metal-ligand ratio, the $\mathrm{pH}$ value and reaction temperature which play important roles to constructing the coordination polymers, the most effective way is to choose suitable organic ligands [20, 21]. The preparation of these LnMOFs can be controlled by the combination of the functionalities of the appropriate organic ligands containing $\mathrm{N}$ - or $\mathrm{O}$-donor atoms and the geometrical preferences of the lanthanide ions [22].

In view of the importance of photoluminescence of the metal organic frameworks and our interest in the chemistry of coordination compounds involving lanthanide based complexes, two $\mathrm{Ln}^{+3}$ based MOFs [ $\mathrm{Ln}=\mathrm{Gd}(\mathbf{1}), \mathrm{Ce}(\mathbf{2})]$ have been synthesized under hydrothermal conditions with using btec ligand. The crystal structure of complex 1 and complex $\mathbf{2}$ were previously reported at room temperature $[23,24]$.

*Corresponding Author:yaseminyahsi@gmail.com 
Herein, the crystal structures of complex $\mathbf{1}$ and complex $\mathbf{2}$ have been re-determined by single crystal $\mathrm{X}$-ray diffraction analysis and characterized by infrared, UV-vis and photoluminescence properties of both complexes will report first time in this work.

\section{EXPERIMENTAL}

\subsection{Materials and Instruments}

Benzene-1,2,4,5-tetracarboxylic acid, $\mathrm{Gd}\left(\mathrm{NO}_{3}\right)_{3} \cdot 6 \mathrm{H}_{2} \mathrm{O}$ and $\mathrm{CeCl}_{3} .7 \mathrm{H}_{2} \mathrm{O}$ have been purchased from Aldrich Chemical Co. Elemental $(\mathrm{C}, \mathrm{H})$ analyses have been carried out by standard methods with a LECO, CHNS-932 analyzer. FT-IR spectra were measured with a Perkin-Elmer Spectrum 65 instrument in the range of $4000-600 \mathrm{~cm}^{-1}$. Solid state UV-visible spectra were measured at room temperature with an Ocean Optics Maya 2000Pro Spectrophotometer. Solid state luminescence spectra in the visible region were measured at room temperature with an ANDOR SR500i-BL Photoluminescence Spectrometer equipped with a triple grating and used an air-cooled CCD camera as detector. The measurements were done by using the excitation source $(349 \mathrm{~nm})$ of a Spectra-physics $\mathrm{Nd}$ :YLF laser with a $5 \mathrm{~ns}$ pulse width and $1.3 \mathrm{~mJ}$ of energy per pulse as the source.

\subsection{Synthesis of Complex (1) $\left[\mathrm{C}_{10} \mathrm{H}_{9} \mathrm{GdO}_{11}\right]$}

Benzene-1,2,4,5-tetracarboxylic acid (btec) $(1 \mathrm{mmol})$ were dissolved in $10 \mathrm{~mL}$ of distilled water and stirred for $30 \mathrm{~min}$ at room temperature. An aqueous solution of $\mathrm{Gd}\left(\mathrm{NO}_{3}\right)_{3} \cdot 6 \mathrm{H}_{2} \mathrm{O}(1 \mathrm{mmol})$ was added into the abovementioned solution. The reaction mixture was placed in a Parr-Teflon lined stainless steel vessel, sealed and heated at $120^{\circ} \mathrm{C}$ for 3 days, followed by slow cooling $\left(5^{\circ} \mathrm{C} \mathrm{h}^{-1}\right)$ to room temperature. After filtration and washing with $\mathrm{H}_{2} \mathrm{O}$, colorless crystals were collected and dried in air. Found: $\mathrm{C}, 25.62 \%$; H, $1.79 \%$. $\mathrm{C}_{10} \mathrm{H}_{9} \mathrm{GdO}_{11}$; Calc.: C, $25.97 \%$; H, $1.96 \%$.

\subsection{Synthesis of Complex (2) $\left[\mathrm{C}_{10} \mathrm{H}_{5} \mathrm{CeO}_{9}\right]$}

The mixture of aqueous solution of $\mathrm{CeCl}_{3} .7 \mathrm{H}_{2} \mathrm{O}(1 \mathrm{mmol})$ and benzene-1,2,4,5-tetracarboxylic acid (1 mmol) was sealed in a $23 \mathrm{~mL}$ Teflon-lined stainless steel container and heated at $120^{\circ} \mathrm{C}$ for 3 days. After the reactor was slowly cooled $\left(5^{\circ} \mathrm{C} \mathrm{h}^{-1}\right)$ to room temperature, colorless crystals of 2 were obtained. Found: C, $29.55 \%$; H, $1.34 \% . \mathrm{C}_{10} \mathrm{H}_{5} \mathrm{CeO}_{9}$; Calc.: C, $29.34 \% ; \mathrm{H}, 1.23 \%$.

\subsection{X-ray Crystallography}

Intensity data for suitable single crystals of $\mathbf{1}$ and $\mathbf{2}$ was collected using Oxford Diffraction Xcalibur-3 diffractometer equipped with a Mo $\mathrm{K}_{\alpha}$ radiation source $(\lambda=0.71073 \AA$ at $296 \mathrm{~K})$. The data collections and data reductions were performed with the CRYSALIS CCD and CRYSALIS RED programs [25]. The structures were solved by direct methods and refined using full-matrix least-squares against $F^{2}$ using SHELXTL [26]. The crystallographic data for $\mathbf{1}$ and $\mathbf{2}$ is listed briefly in Table 1. Molecular drawings were obtained using MERCURY [27].

\section{RESULTS AND DISCUSSION}

\subsection{Crystal Structure Description of (1)}

The molecular structure of $\mathbf{1}$ with atom numbering scheme is given in Figure 1 and some selected bond lengths and angles are listed in Table 2. The X-ray structure analysis of complex $\mathbf{1}$ shows that each $\mathrm{Gd}(\mathrm{III})$ ion is nine-coordinated in which eight oxygen atoms from btec ligands with the $\mathrm{Gd}-\mathrm{O}$ bond distances in the range of 2.344 (4)-2.572 (3) $\AA$ and one oxygen atom from coordinated water molecule with the $\mathrm{Gd}-\mathrm{O}$ bond distance of 2.368 (4) $\AA$. All bond distances and angles are comparable to similar structures [28-30]. The coordination environment around Gd(III) ion can be described as distorted monocapped square-antiprism geometry. As seen in Figure 1, the crystal structure of $\mathbf{1}$ has two crystallographically independent btec ligands which have inversion centre in the center of their 
aromatic rings. In complex $1, \mathrm{Gd}(\mathrm{III})$ atoms have been connected by $\mu$-oxo carboxylate $_{\text {bridges from btec }}$ ligands to form 2D layers and these layers are further interlinked via strong $\mathrm{O}-\mathrm{H} \cdots \mathrm{O}$ hydrogenbonding interactions resulting in 3D architecture (Figure 2).

Table 1. Crystal data and structure refinements for (1) and (2)

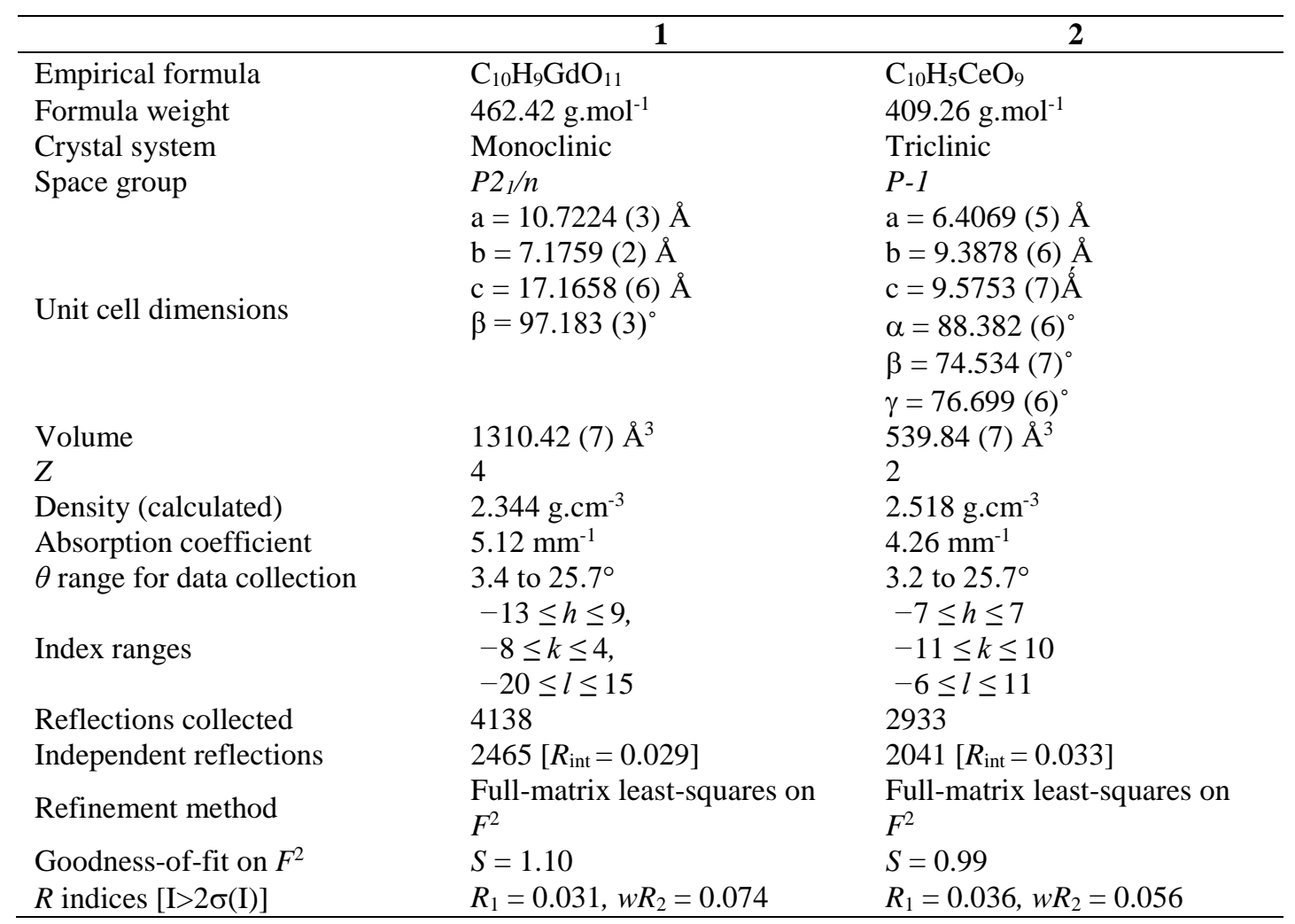

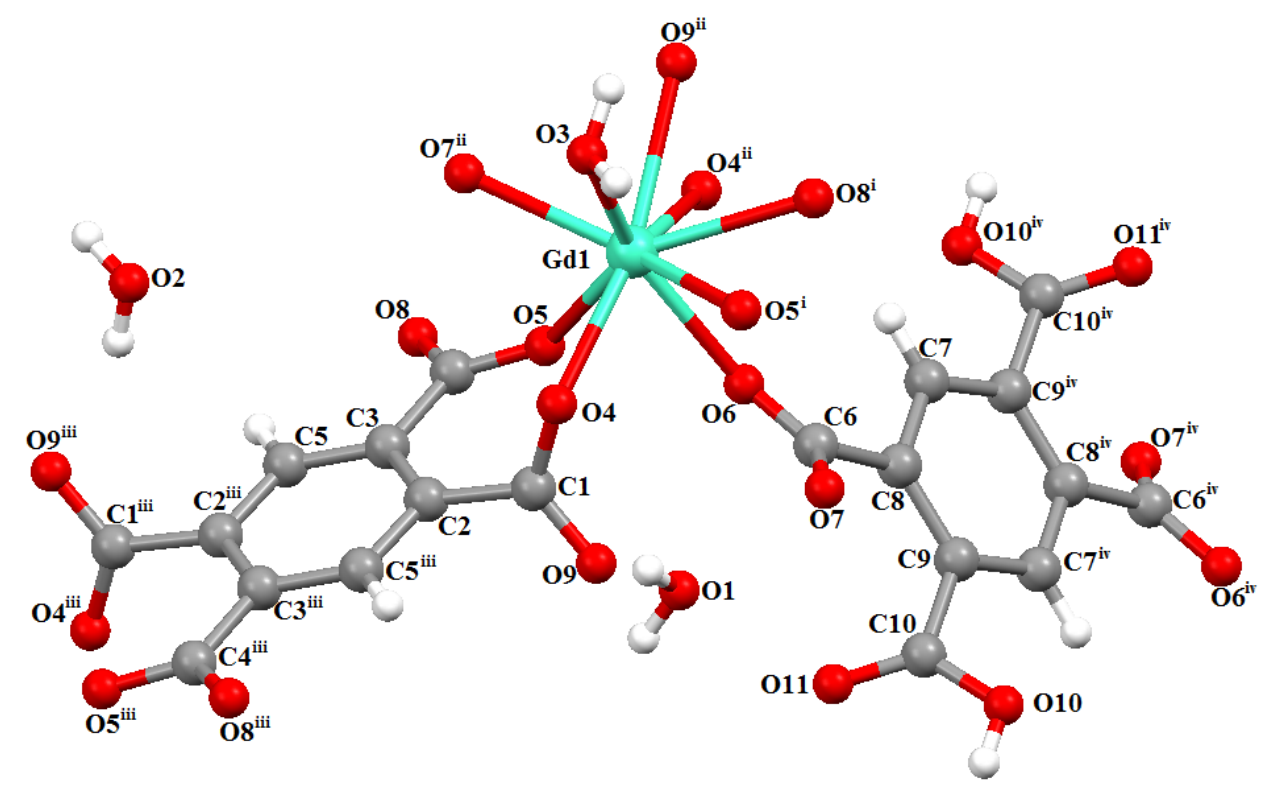

Figure 1. Part of the polymeric structure of complex 1, showing the atom labelling scheme. [Symmetry code(s): (i) $-x+1 / 2, y+1 / 2,-z+1 / 2$; (ii) $-x+1 / 2, y-1 / 2,-z+1 / 2$; (iii) $-x+1,-y+1$, $-z+1$; (iv) $-x+1,-y+1,-z$.] 


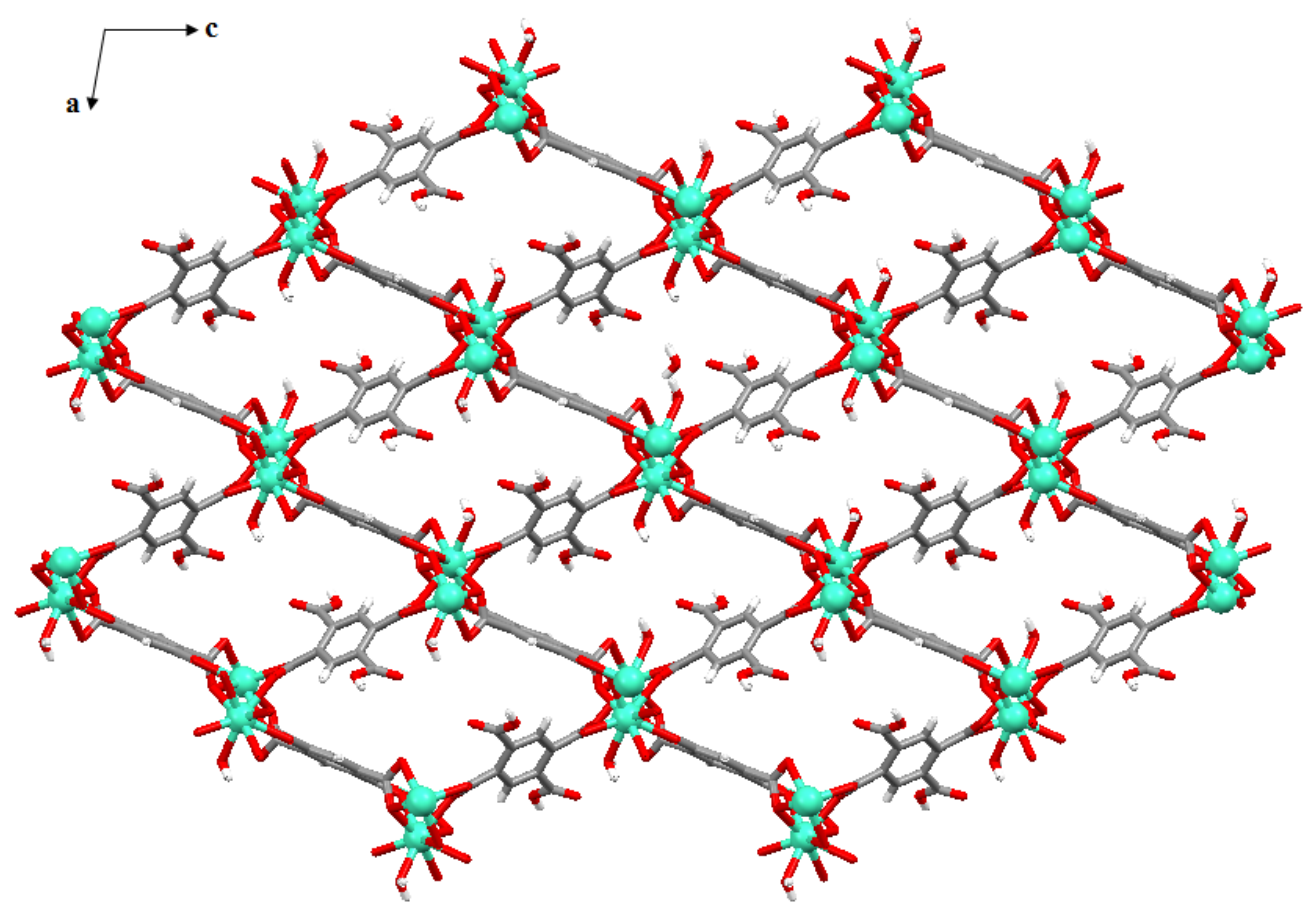

Figure 2. The molecular packing diagram of complex $\mathbf{1}$ in the $a c$-plane $\left(\mathrm{H}_{2} \mathrm{O}\right.$ molecules have been omitted for clarity)

Table 2. Some selected bond lengths $[\AA]$ and angles $\left[{ }^{\circ}\right]$ for $(\mathbf{1})$

\begin{tabular}{|c|c|c|c|}
\hline \multicolumn{4}{|c|}{ Bond lengths $(\AA)$} \\
\hline $\mathrm{Gd} 1-\mathrm{O} 3$ & $2.368(4)$ & Gd1-O6 & $2.344(4)$ \\
\hline $\mathrm{Gd} 1-\mathrm{O} 4$ & $2.367(3)$ & $\mathrm{Gd} 1-\mathrm{O} 7^{\mathrm{ii}}$ & $2.374(4)$ \\
\hline $\mathrm{Gd} 1-\mathrm{O} 4^{\mathrm{ii}}$ & $2.484(3)$ & $\mathrm{Gd} 1-\mathrm{O} 8^{\mathrm{i}}$ & $2.478(4)$ \\
\hline $\mathrm{Gd} 1-\mathrm{O} 5$ & $2.417(3)$ & $\mathrm{Gd} 1-\mathrm{O} 9^{\mathrm{ii}}$ & $2.572(3)$ \\
\hline $\mathrm{Gd} 1-\mathrm{O} 5^{\mathrm{i}}$ & $2.553(3)$ & & \\
\hline \multicolumn{4}{|l|}{ Bond Angles ( $\left.{ }^{\circ}\right)$} \\
\hline O3-Gd1-O5 & $138.31(15)$ & O6-Gd1-O5 & $70.68(13)$ \\
\hline $\mathrm{O} 4-\mathrm{Gd} 1-\mathrm{O} 4^{\mathrm{ii}}$ & $139.39(6)$ & $\mathrm{O} 6-\mathrm{Gd} 1-\mathrm{O} 7^{\mathrm{ii}}$ & $143.71(13)$ \\
\hline O4-Gd1-O5 & $73.11(11)$ & 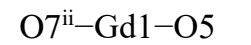 & $73.03(12)$ \\
\hline $\mathrm{O} 4-\mathrm{Gd} 1-\mathrm{O} 9^{\mathrm{ii}}$ & $165.51(12)$ & $\mathrm{O} 7^{\mathrm{ii}-}-\mathrm{Gd} 1-\mathrm{O}^{\mathrm{i}}$ & $138.64(13)$ \\
\hline $\mathrm{O} 5-\mathrm{Gd} 1-\mathrm{O} 5^{\mathrm{i}}$ & $133.43(8)$ & $\mathrm{O} 9^{\mathrm{ii}}-\mathrm{Gd} 1-\mathrm{Gd} 1^{\mathrm{i}}$ & $148.89(9)$ \\
\hline $\mathrm{O} 6-\mathrm{Gd} 1-\mathrm{O} 3$ & $143.64(14)$ & $\mathrm{Gd} 1-\mathrm{O} 4-\mathrm{Gd} 1^{\mathrm{i}}$ & $108.10(14)$ \\
\hline O6-Gd1-O4 & $78.60(13)$ & $\mathrm{Gd} 1-\mathrm{O} 5-\mathrm{Gd} 1^{1 \mathrm{ii}}$ & 104.39 (12) \\
\hline
\end{tabular}

\subsection{Crystal Structure Description of (2)}

The structure of complex 2 with atom numbering scheme is given in Figure 3. The X-ray structure analysis of complex 2 shows that each Ce(III) ion is coordinated by nine oxygen atoms in which eight from btec ligands with the $\mathrm{Ce}-\mathrm{O}$ bond distances in the range of 2.407 (4)-2.642 (3) $\AA$ and one from water molecule with the $\mathrm{Ce}-\mathrm{O}$ bond distance of 2.476 (5) $\AA$. The shortest non-bonding $\mathrm{Ce} . . \mathrm{Ce}$ distance is 4.392 A. Some selected bond lengths and angles are listed in Table 3, which lie well within the range of reported values for corresponding bond lengths and angles of similar $\mathrm{Ce}$ (III) complexes $[19,31,32]$. Structural analysis shows that the polymeric chains of Ce(III) complex are linked with carboxylate oxygens of btec ligands to form 2D layer which lead to a $3 \mathrm{D}$ network via hydrogen bonding interactions (Figure 4). 


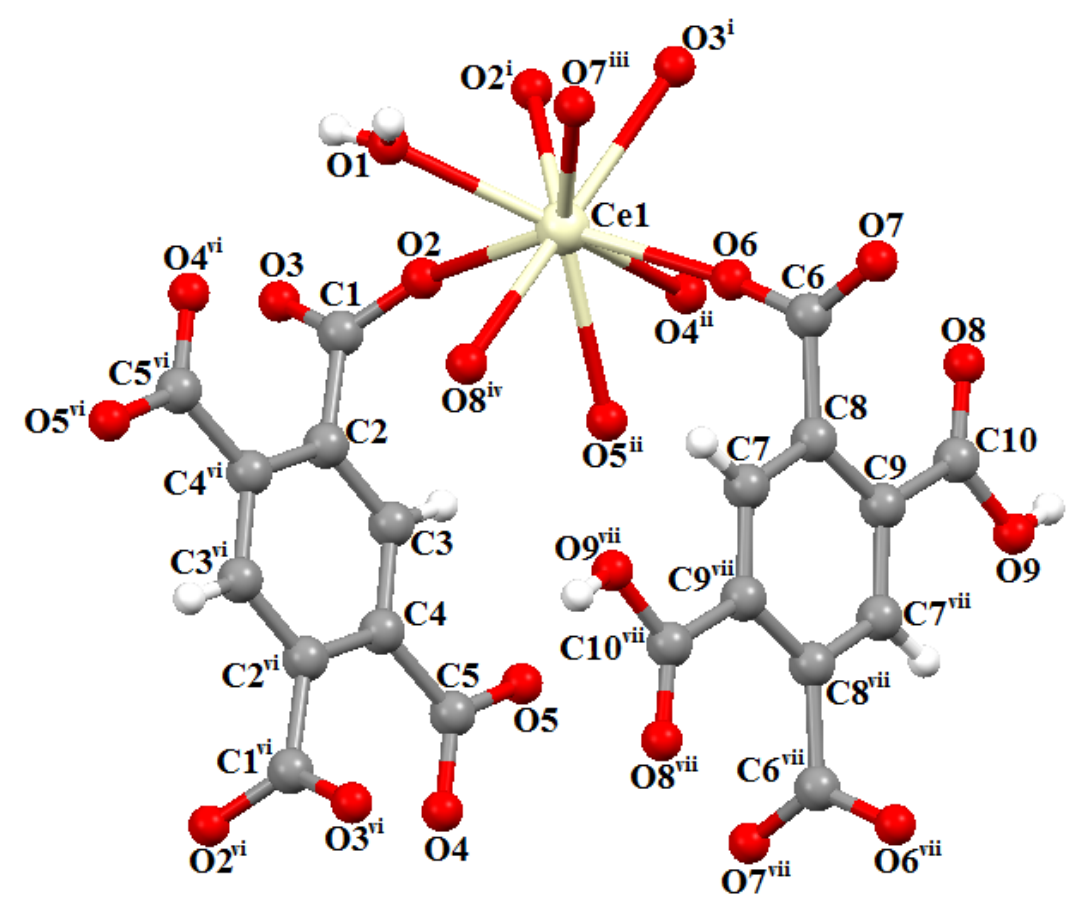

Figure 3. Part of the polymeric structure of complex 2, showing the atom labelling scheme. [Symmetry code(s): (i) $-x+1,-y,-z+1$; (ii) $-x+1,-y+1,-z+1$; (iii) $-x+2,-y,-z$; (iv) $x-1$, $y, z$; (v) $x+1, y, z$; (vi) $-x,-y+1,-z+1$; (vii) $-x+2,-y+1,-z$.]

Table 3. Some selected bond lengths $[\AA]$ and angles $\left[^{\circ}\right]$ for (2)

\begin{tabular}{llll}
\hline Bond lengths $(\AA)$ & & & \\
\hline $\mathrm{Ce} 1-\mathrm{O} 1$ & $2.476(5)$ & $\mathrm{Ce} 1-\mathrm{O} 5^{\mathrm{ii}}$ & $2.571(4)$ \\
$\mathrm{Ce} 1-\mathrm{O} 2$ & $2.642(3)$ & $\mathrm{Ce} 1-\mathrm{O} 6$ & $2.407(4)$ \\
$\mathrm{Ce} 1-\mathrm{O} 2^{\mathrm{i}}$ & $2.524(4)$ & $\mathrm{Ce} 1-\mathrm{O} 7^{\mathrm{iii}}$ & $2.456(5)$ \\
$\mathrm{Ce} 1-\mathrm{O} 3^{\mathrm{ii}}$ & $2.534(3)$ & $\mathrm{Ce} 1-\mathrm{O} 8^{\mathrm{iv}}$ & $2.553(4)$ \\
$\mathrm{Ce} 1-\mathrm{O} 4^{\mathrm{ii}}$ & $2.589(4)$ & & \\
\hline Bond Angles $\left(^{\circ}\right.$ & & & \\
\hline $\mathrm{O} 1-\mathrm{Ce} 1-\mathrm{O} 2$ & $70.26(19)$ & $\mathrm{O} 6-\mathrm{Ce} 1-\mathrm{O} 3^{\mathrm{i}}$ & $81.35(12)$ \\
$\mathrm{O} 1-\mathrm{Ce} 1-\mathrm{O} 3^{\mathrm{i}}$ & $102.48(15)$ & $\mathrm{O} 6-\mathrm{Ce} 1-\mathrm{O} 5^{\mathrm{ii}}$ & $72.38(13)$ \\
$\mathrm{O} 1-\mathrm{Ce} 1-\mathrm{O} 4^{\mathrm{ii}}$ & $145.99(18)$ & $\mathrm{O} 7^{\mathrm{iii}}-\mathrm{Ce} 1-\mathrm{O} 2$ & $136.64(12)$ \\
$\mathrm{O} 1-\mathrm{Ce} 1-\mathrm{O} 5^{\mathrm{ii}}$ & $130.37(17)$ & $\mathrm{O} 7^{\mathrm{iii}}-\mathrm{Ce} 1-\mathrm{O} 3^{\mathrm{i}}$ & $72.54(13)$ \\
$\mathrm{O} 2-\mathrm{Ce} 1-\mathrm{O} 2^{\mathrm{i}}$ & $63.58(13)$ & $\mathrm{O} 7^{\mathrm{iii}}-\mathrm{Ce} 1-\mathrm{O} 5^{\mathrm{ii}}$ & $142.73(13)$ \\
$\mathrm{O} 2-\mathrm{Ce} 1-\mathrm{O} 3^{\mathrm{i}}$ & $112.88(12)$ & $\mathrm{O} 7^{\mathrm{iii}}-\mathrm{Ce} 1-\mathrm{O} 8^{\mathrm{iv}}$ & $88.18(13)$ \\
$\mathrm{O} 2-\mathrm{Ce} 1-\mathrm{O} 5^{\mathrm{ii}}$ & $73.19(12)$ & $\mathrm{O} 8^{\mathrm{ii}}-\mathrm{Ce} 1-\mathrm{O} 2^{\mathrm{i}}$ & $143.19(12)$ \\
$\mathrm{O} 3^{\mathrm{i}}-\mathrm{Ce} 1-\mathrm{O} 5^{\mathrm{ii}}$ & $122.29(12)$ & $\mathrm{O} 8^{\mathrm{i}}-\mathrm{Ce} 1-\mathrm{O} 4^{\mathrm{ii}}$ & $120.48(12)$ \\
$\mathrm{O} 3^{\mathrm{i}}-\mathrm{Ce} 1-\mathrm{O} 8^{\mathrm{iv}}$ & $159.86(15)$ & $\mathrm{O} 8^{\mathrm{iv}}-\mathrm{Ce} 1-\mathrm{O} 5^{\mathrm{ii}}$ & $70.37(12)$ \\
$\mathrm{O} 4^{\mathrm{ii}}-\mathrm{Ce} 1-\mathrm{O} 2^{\mathrm{i}}$ & $74.68(11)$ & $\mathrm{O} 8^{\mathrm{iv}}-\mathrm{Ce} 1-\mathrm{C} 1^{\mathrm{i}}$ & $162.74(13)$ \\
$\mathrm{O} 5^{\mathrm{ii}}-\mathrm{Ce} 1-\mathrm{O} 2^{\mathrm{i}}$ & $114.15(13)$ & $\mathrm{O} 8^{\mathrm{i}}-\mathrm{Ce} 1-\mathrm{C} 5^{\mathrm{ii}}$ & $95.59(13)$ \\
$\mathrm{O} 6-\mathrm{Ce} 1-\mathrm{O} 1$ & $140.2(2)$ & $\mathrm{C} 1^{\mathrm{i}}-\mathrm{Ce} 1-\mathrm{C} 5^{\mathrm{ii}}$ & $98.93(14)$ \\
$\mathrm{O} 6-\mathrm{Ce} 1-\mathrm{O} 2$ & $145.08(13)$ & $\mathrm{Ce} 1-\mathrm{O} 2-\mathrm{Ce} 1^{\mathrm{i}}$ & $116.42(13)$ \\
\hline
\end{tabular}

[Symmetry code(s): (i) $-x+1,-y,-z+1$; (ii) $-x+1,-y+1,-z+1$; (iii) $-x+2,-y,-z$; (iv) $x-1, y, z$; (v) $x+1$, $y, z$; (vi) $-x,-y+1,-z+1$; (vii) $-x+2,-y+1,-z$.] 


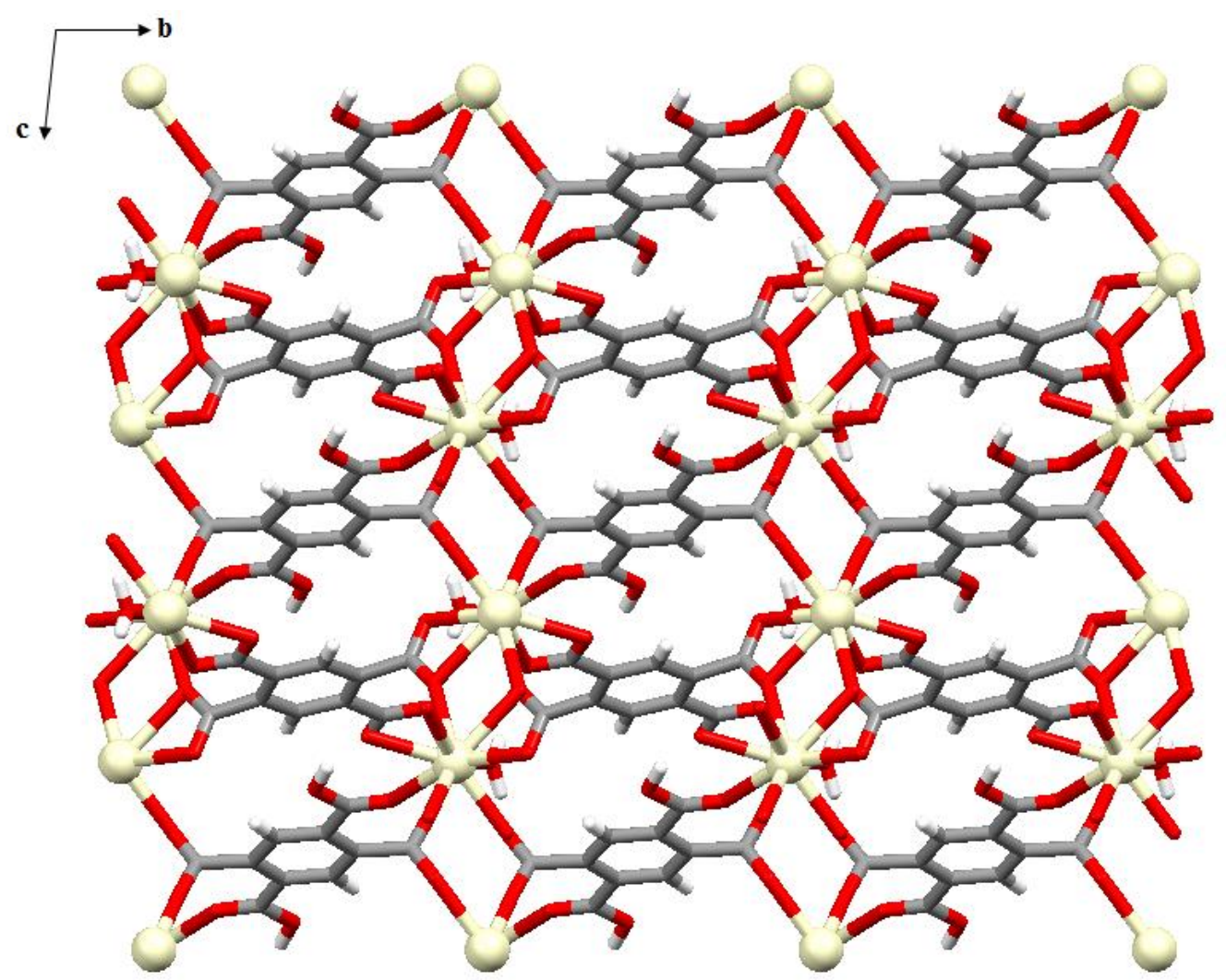

Figure 4. The molecular packing diagram of complex 2 in the $b c$-plane.

\subsection{IR Spectra}

The bands observed at $3400 \mathrm{~cm}^{-1}$ for complex 1 and $3122 \mathrm{~cm}^{-1}$ for complex 2 are attributed to the $\mathrm{O}-\mathrm{H}$ stretching vibration of water molecules involved in extensive hydrogen bonding interactions [33]. The coordinated water also exhibits the frequencies of $655 \mathrm{~cm}^{-1}$ for complex 1 and $645 \mathrm{~cm}^{-1}$ for complex 2, which are assigned to $\rho_{\mathrm{r}}\left(\mathrm{H}_{2} \mathrm{O}\right)$ [34]. The bands at 774 and $762 \mathrm{~cm}^{-1}$ are ascribed to $\mathrm{O}-\mathrm{Gd}-\mathrm{O}$ stretching and the harmonic frequencies of $\mathrm{Gd}-\mathrm{O}$ are characteristic of 836 and $881 \mathrm{~cm}^{-1}$. The observed bands at 755 and $773 \mathrm{~cm}^{-1}$ are assignable to the $\mathrm{O}-\mathrm{Ce}-\mathrm{O}$ stretching and the bands at 811 and $861 \mathrm{~cm}^{-1}$ are characteristic of $\mathrm{Ce}-\mathrm{O}$ stretching vibration. The observed bands in the range of 1496-1657 $\mathrm{cm}^{-1}$ for complex 1 and $1525-1721 \mathrm{~cm}^{-1}$ for complex 2 are characteristics of carboxylic groups. Thus the infrared spectrums are found to be in good agreement with the x-ray structures of the complex 1 and 2.

\subsection{Photoluminescence Properties}

The solid-state luminescent properties of the free btec ligand, complex $\mathbf{1}$ and complex $\mathbf{2}$ were investigated at room temperature in the visible regions upon excitation at $\lambda_{\mathrm{ex}}=349 \mathrm{~nm}$ (Figure 5). The free btec ligand shows broad emission bands at $\lambda_{\max 1}=417 \mathrm{~nm}$ and $\lambda_{\max 2}=504 \mathrm{~nm}$ which may be assigned to the $n \rightarrow \pi^{*}$ or $\pi \rightarrow \pi^{*}$ electronic transition intraligand charge transfer (ILCT) [35-37]. The emission spectrum of complex $\mathbf{1}$ indicates a wide band and intense cyan-blue emission with the maximum wavelength of $527 \mathrm{~nm}$, while, two emission bands are observed of the btec ligand in the same region (Figure 5a). The metal centered (MC) electronic levels of Gd(III) are known to be located at $31000 \mathrm{~cm}^{-1}$, which is well above the ligand-centered (LC) electronic levels of the btec ligand (see Figure 6). Thus, the first excited state ${ }^{6} \mathrm{P}_{7 / 2}$ of the $\mathrm{Gd}^{\mathrm{III}}$ is too high to accept the energy from the triplet excited state of the btec ligand, therefore, the energy transfer from the btec ligand to the metal center 
and the MC luminescence cannot be observed in complex 1. The observed red shift of the emission maximum of complex 1 was considered to originate mainly from the influence of the coordination of the Gd(III) to the btec ligand [37-39]. In comparison of the other Gd(III) based polymers, the observed wide band emission for complex 1 is similar to the reported in literature previously [40, 41]. Complex 2 exhibits intense blue emission, and a broad band spectra can be observed from 350 to $600 \mathrm{~nm}$ with the maximum wavelength of $480 \mathrm{~nm}$, while, two emission bands are observed of the btec ligand in the same region. The configuration of $\mathrm{Ce}$ (III) consist of two multiplets, the ${ }^{2} \mathrm{~F}_{5 / 2}$ level of the ground state and the ${ }^{2} \mathrm{~F}_{7 / 2}$ level of the excited state (see Figure 6). Mostly, the Ce(III) has a strong UV absorption [42] and may exhibit a broad band of luminescence in the blue spectral regions from the lowest crystal field level of the excited state $5 \mathrm{~d}^{1}$ to the ${ }^{2} \mathrm{~F}_{5 / 2}$ and ${ }^{2} \mathrm{~F}_{7 / 2}$ levels of the ground configuration $4 \mathrm{f}^{1}$ [43]. So this blue emission for complex 2 may be attributed to the characteristic emission of ${ }^{2} \mathrm{~F}_{5 / 2} \rightarrow{ }^{2} \mathrm{D}_{3 / 2}$ transition of $\mathrm{Ce}$ (III) or combined effect of the ligand-centered (LC) fluorescence [41, 43]. In comparison of the other Ce(III) based polymers, the observed emission band for complex $\mathbf{2}$ is similar to the reported in literature previously $[40,41]$.

The Energy Transfer mechanism and energy level diagrams of Ce(III) and Gd(III) ions are shown in Figure 6. According to Latva's empirical rule, the suitable energy gap is $2500-4000 \mathrm{~cm}^{-1}$ for ligand to metal energy transfer process for lanthanide ions. For btec ligand, the singlet energy level $\left(\mathrm{S}_{1}\right)$ is $27000 \mathrm{~cm}^{-1}(371 \mathrm{~nm})$ and the triplet lowest energy level is $24000 \mathrm{~cm}^{-1}(417 \mathrm{~nm})$ (see Figure 5 and Figure 7). The energy gap $\Delta \mathrm{E}\left(\mathrm{S}_{1}-\mathrm{T}_{1}\right)$ for the btec ligand is $3000 \mathrm{~cm}^{-1}$. Thus, the intersystem crossing (ISC) is effective for the btec ligand [44]. For complex 2, the experimentally observed $\left(\mathrm{T}_{1}\right)$ energy level of the btec ligand is $3200 \mathrm{~cm}^{-1}$ which is higher than the ${ }^{2} \mathrm{D}_{3 / 2}$ level of $\mathrm{Ce}$ (III) ion. This phenomenon indicates that the transition from the triplet energy level of the btec ligand to $\mathrm{Ce}(\mathrm{III})$ is effective.

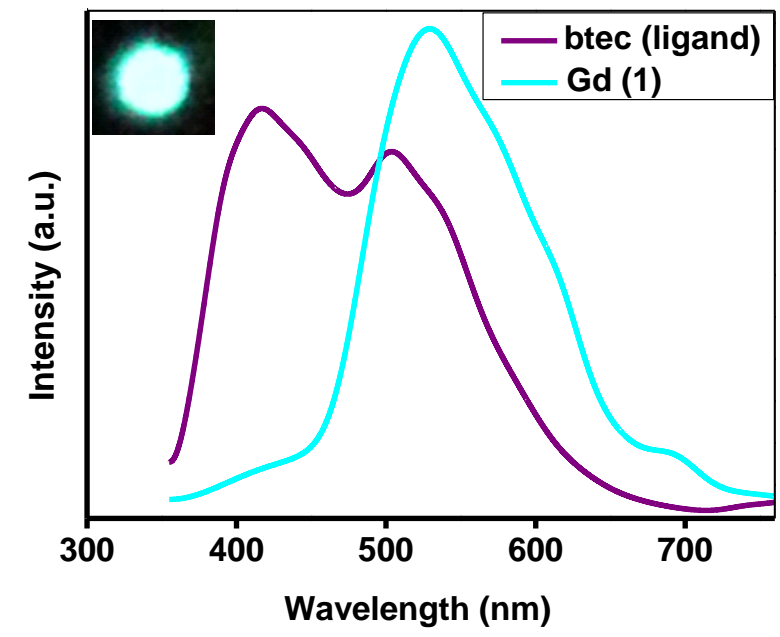

(a)

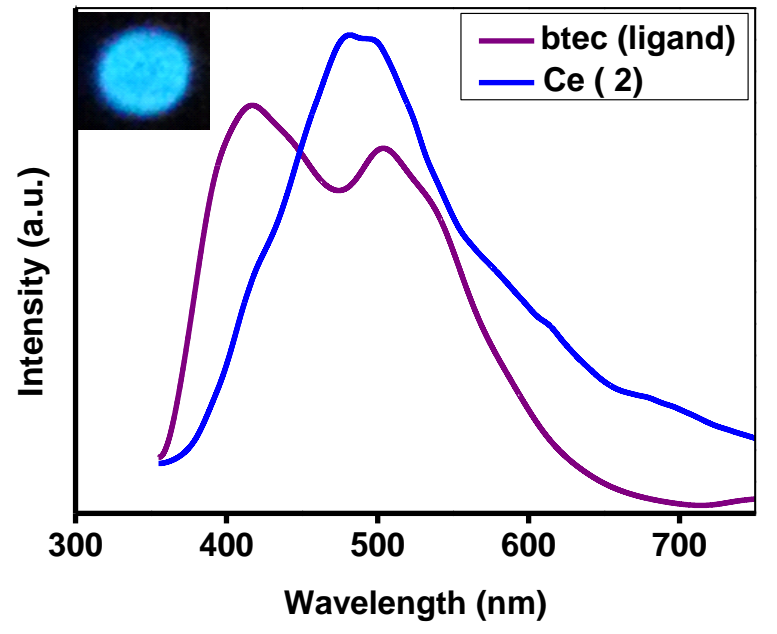

(b)

Figure 5. The emission spectrums of the free ligand (btec), complex 1 (upper) and complex 2 (bottom) in the solid samples at room temperature $\left(\lambda_{\text {exc. }}=349 \mathrm{~nm}\right)$. 


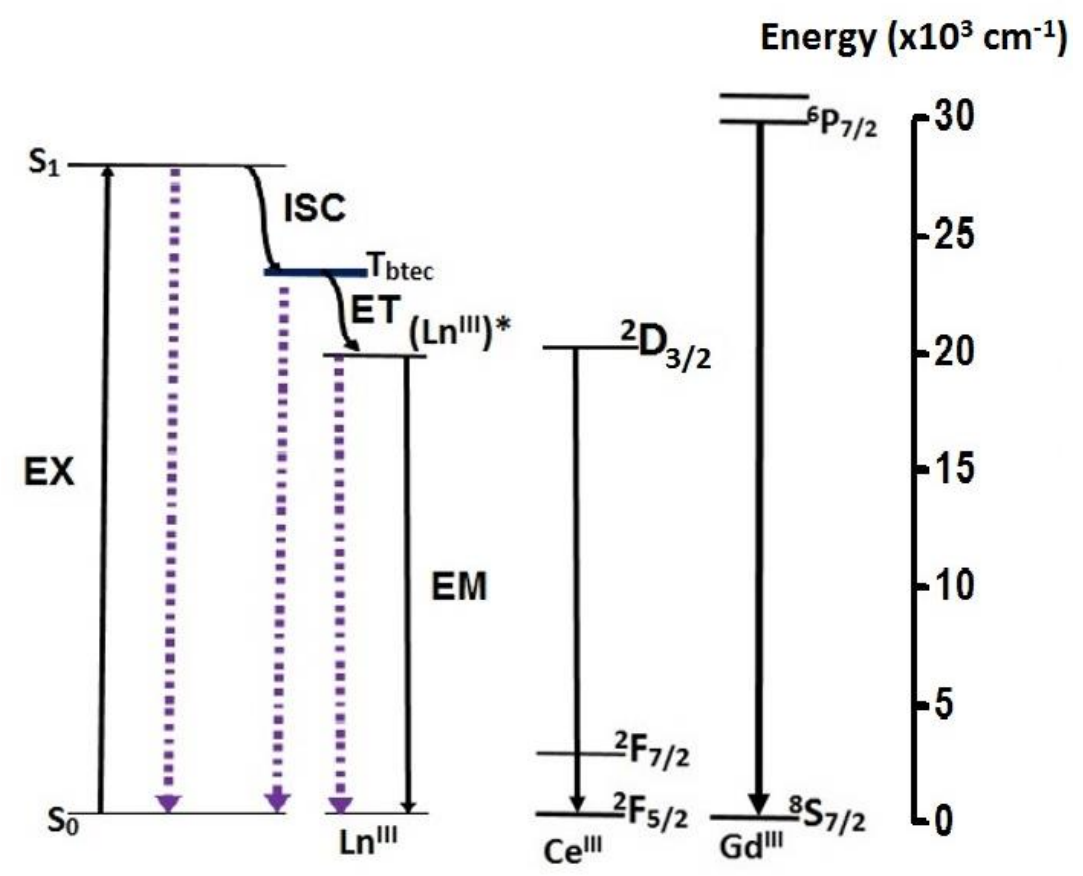

Figure 6. The Energy Transfer mechanism (left) and energy level diagrams of Ce(III) and Gd(III) ions (right)

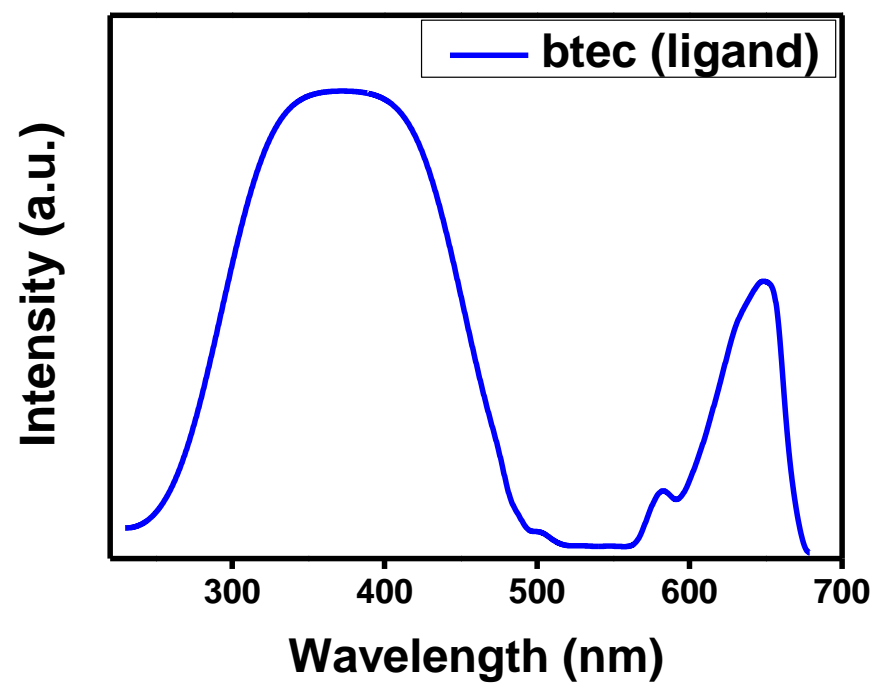

Figure 7. UV-Vis absorption spectrum of the btec ligand in solid state

\section{CONCLUSIONS}

Two $\mathrm{Ln}^{+3}$ based MOFs ( $\mathrm{Ln}=\mathrm{Gd}, \mathrm{Ce}$ ) have been synthesized successfully under hydrothermal conditions with using 1,2,4,5-benzenetetracarboxylate (btec) ligand. The crystal structures of these LnMOFs have been redetermined by single crystal X-ray diffraction analysis. And both complexes characterized by also elemental analysis, UV-Visible and infrared spectroscopy. Structural analysis of $\mathrm{Gd}(\mathrm{III})$ and $\mathrm{Ce}$ (III) complexes shows that each lanthanide ion is nine coordinated by oxygen atoms of btec ligands. For both complexes, $\mathrm{Gd}(\mathrm{III})$ and $\mathrm{Ce}(\mathrm{III})$ lanthanide ions are bridged by $\mu$-oxo $\mathrm{o}_{\text {carboxylate }}$ 
oxygens from btec ligands to form polymeric chains which lead to 2D layers. And these layers are further interlinked via strong hydrogen bonding interactions resulting in 3D networks. In accordance with the main purpose of this study, solid-state luminescent properties have been investigated at room temperature for btec ligand, complex $\mathbf{1}$ and 2. The solid-state photoluminescence measurements display intense cyan-blue emission for complex $\mathbf{1}$ and blue emission for complex $\mathbf{2}$ in the visible regions.

\section{ACKNOWLEDGEMENTS}

The author is grateful to the Research Funds of Balikesir University (BAP-2016/105) for the financial support. The author is grateful to Dr. Muhittin Aygun and to Dokuz Eylül University for the use of the Agilent Xcalibur Eos diffractometer (purchased under University Research Grant No. 2010.KB.FEN.13). The author also acknowledges to Balikesir University, Science and Technology Application and Research Center (BUBTAM) for the use of the Photoluminescence Spectrometer and to Dr. Hulya Kara and Burak Coban for their helpful and constructive suggestions.

\section{REFERENCES}

[1] Zhao B, Chen XY, Cheng P, Liao DZ, Yan SP, Jiang ZH. Coordination Polymers Containing 1D Channels as Selective Luminescent Probes J. Am. Chem. Soc. 2004; 126: 15394-15395.

[2] Guo ZY, Wu H, Srinivas G, Zhou YM, Xiang SC, Chen ZX, Yang YT, Zhou W, O'Keeffe M, Chen BL. A Metal-Organic Framework with Optimized Open Metal Sites and Pore Spaces for High Methane Storage at Room Temperature. Angew. Chem. Int. Ed. 2011; 50: 3178-3181.

[3] Jiang CY, Wu T, Zheng ST, Zhao X, Lin QP, Bu XH, Feng PY. A Nine-Connected Mixed-Ligand Nickel-Organic Framework and Its Gas Sorption Properties. Cryst. Growth Des. 2011; 11: 37133716 .

[4] Getman RB, Bae YS, Wilmer CE, Snurr RQ. Review and Analysis of Molecular Simulations of Methane, Hydrogen, and Acetylene Storage in Metal-Organic Frameworks. Chem. Rev. 2012; 112: 703-723.

[5] Bao SS, Ma LF, Wang Y, Fang L, Zhu CJ, Li YZ, Zheng LM. Anion-Directed Self-Assembly of Lanthanide-notp Compounds and Their Fluorescence, Magnetic, and Catalytic Properties. Chem. Eur. J. 2007; 13: 2333-2343.

[6] Lin ZJ, Yang Z, Liu TF, Huang YB, Cao R. Microwave-Assisted Synthesis of a Series of Lanthanide Metal-Organic Frameworks and Gas Sorption Properties. Inorg. Chem. 2012; 51: 18131820.

[7] Cañadillas-Delgado L, Fabelo O, Pasán J, Julve M, Lloret F, Ruiz-Pérez C. All-cis-1,2,3,4,5,6cyclohexanehexacarboxylate two-dimensional gadolinium(III) complexes: Synthesis, X-ray crystal structure and magnetic properties. Polyhedron 2010; 29: 188-195.

[8] Zhu HF, Fan J, Okamura T, Zhang ZH, Liu GX, Yu KB, Sun WY, Ueyama N. Metal-Organic Architectures of Silver(I), Cadmium(II), and Copper(II) with a Flexible Tricarboxylate Ligand. Inorg. Chem. 2006; 45: 3941-3948.

[9] Cao X, Yu L, Huang R. Two Ce-containing 3D metal-organic frameworks: In situ formation of ligand (DDPD). Journal of Solid State Chemistry 2014; 210: 74-78. 
[10] Rodrigues CV, Luz LL, Dutra JDL, Junior SA, Malta OL, Gatto CC, Streit HC, Freire RO, Wickleder C, Rodrigues MO. Unusual photoluminescence properties of the 3D mixed-lanthanideorganic frameworks induced by dimeric structures: a theoretical and experimental approach. Phys. Chem. Chem. Phys. 2014; 16: 14858-14866.

[11] Lu Z, Wen L, Yao J, Zhu H, Meng Q. Two types of novel layer framework structures assembled from 5-sulfosalicylic acid and lanthanide ions. CrystEngComm, 2006; 8: 847-853.

[12] Zhang JL, Ji H, Wei YG, Wang Y, Wu NZ. Low-Temperature Synthesis of Superparamagnetic Nanocomposite Particles Composed of Platinum and Maghemite. J. Phys. Chem. C 2008; 112: 1068810691.

[13] Cañadillas-Delgado L, Fabelo O, Pasan J, Delgado FS, Lloret F, Julve M, Ruiz-Perez C. Intramolecular ferro- and antiferromagnetic interactions in oxo-carboxylate bridged digadolinium(III) complexes. Dalton Trans. 2010; 39: 7286-7293.

[14] Dong LJ, Chu W, Zhu QL, Huang RD. Three Novel Homochiral Helical Metal-Organic Frameworks Based on Amino Acid Ligand: Syntheses, Crystal Structures, and Properties. Cryst. Growth Des. 2011; 11 (1): 93-99.

[15] Hashimoto M, Igawa S, Yashima M, Kawata I, Hoshino M, Osawa M. Highly Efficient Green Organic Light-Emitting Diodes Containing Luminescent Three-Coordinate Copper(I) Complexes. J. Am. Chem. Soc. 2011; 133 (37): 10348-10351.

[16] Dong LJ, Li XF, Cao J, Chu W, Huang RD. An $\alpha$-Keggin polyoxometalate completely constructed from the late transition metal CoII as poly atom. Dalton Trans. 2013; 42: 1342-1345.

[17] Kentc CA, Liu D, Meyer TJ, Lin W. Amplified Luminescence Quenching of Phosphorescent Metal-Organic Frameworks. J. Am. Chem. Soc. 2012; 134 (9): 3991-3994.

[18] Lee YR, Kim J, Ahn WS. Synthesis of metal-organic frameworks: A mini review. Korean J. Chem. Eng. 2013; 30(9): 1667-1680.

[19] Lv YK, Feng YL, Cheng JW. Two new Cerium-Organic Frameworks with unusual network topologies constructed by racemic tartaric acid involving in situ reaction. Inorganic Chemistry Communications 2012; 15: 130-135.

[20] Hopa C, Cokay I. Synthesis, structural characterization and thermal properties of a new copper(II) one-dimensional coordination polymer based on bridging N,N'-bis(2-hydroxybenzylidene)-2,2-dimethylpropane-1,3-diamine and dicyanamide ligands. Acta Crystallogr. Sect. C Struct. Chem. 2016; 72: $149-154$.

[21] Yahsi Y, Ozbek H, Aygun M, Kara H. Crystal structure and photoluminescence properties of a new $\mathrm{Cd}^{\mathrm{II}}$ coordination polymer catena-poly[bis[4-bromo-2-(\{[2-(pyrrolidin-1-yl)ethyl]imino $\}$ methyl)phenolato- $\left.\kappa 3 \mathrm{~N}, \mathrm{~N}^{\prime}, \mathrm{O}\right] \mathrm{di}-\mu 3$-chlorido-di- $\mu 2$-chlorido-bis(methanol- $\left.\kappa \mathrm{O}\right)$ tricadmium(II)]. Acta Cryst. 2016; C72: 426-431.

[22] Mohammadinasab R, Tabatabaee M, Kukovec BM, Aghaie H. The cerium(III) coordination polymer with mixed polycarboxylic acids. Preparation of the $\mathrm{CeO}_{2}$ nanoparticles by thermal decomposition of the polymer. Inorganica Chimica Acta 2013; 405: 368-373.

[23] Cañadillas-Delgado L, Pasán J, Fabelo O, Julve M, Lloret F, Ruiz-Pérez C. A step further in the comprehension of the magnetic coupling in gadolinium(III)-based carboxylate complexes. Polyhedron 2013; 52: 321-332. 
[24] Ren MJ, Zhang Z, Zhao P, Zhang J. Three-Dimensional Metal-Organic Hybrid Material Bearing an Open-Framework Self-Assembled by Mononuclear Cerium Benzene Tetracarboxylate Complex. Asian Journal of Chemistry 2008; 20: 3687-3701.

[25] Oxford Diffraction Ltd., Version 1.171.31.2.

[26] SHELXTL, Rev. 5.0, Bruker AXS, Madison, WI, USA.

[27] MERCURY 1.4.2, Copyright from CCDC 2001-2007.

[28] John, D, Urland W. Crystal Structure and Magnetic Behaviour of the New Gadolinium Complex Compound $\mathrm{Gd}_{2}\left(\mathrm{ClH}_{2} \mathrm{CCOO}\right)_{6}$ (bipy) $)_{2}$. Eur. J. Inorg. Chem. 2005; 2 (22): 4486-4489.

[29] Zhang H, Lin SY, Xue S, Wang C, Tang J. Acetato-bridged dinuclear lanthanide complexes with single molecule magnet behaviour for the Dy2 species. Dalton Trans. 2014; 43: 6262-6268.

[30] Hong XL, Li YZ, Hu H, Pan Y, Bai J, You XZ. Synthesis, Structure, Luminescence, and Water Induced Reversible Crystal-to-Amorphous Transformation Properties of Lanthanide(III) Benzene-1,4dioxylacetates with a Three-Dimensional Framework. Crystal Growth \& Design 2006; 6 (6): 1221 1226.

[31] Zhou RS, Ye L, Ding H, Song JF, Xu XY, Xu JQ. Syntheses, structures, luminescence, and magnetism of four 3D lanthanide 5-sulfosalicylates. Journal of Solid State Chemistry 2008; 181: 567575.

[32] Zhao W, Zhang LJ, Zhao XL. Structural variations and photoluminescent properties of a series of metal-organic frameworks constructed from 5-(4-carboxybenzoylamino)-isophthalic acid. Journal of Solid State Chemistry 2013; 202: 250-256.

[33] Berti E, Cecconi F, Ghilardi CA, Midollini S. Isostructural organic-inorganic hybrids of $P, P^{\prime}-$ diphenyl-methylenediphosphinate $\left(\mathrm{CH}_{2}\left(\mathrm{P}(\mathrm{Ph}) \mathrm{O}_{2}\right)_{2}\right)_{2}-$ with divalent transition metals. Inorg. Chem. Commun. 2002; 5: 1041-1043.

[34] Nakamoto K. Infrared and Raman Spectra of Inorganic and Coordination Compounds. A WileyInterscience Publication, John Wiley \& Sons, Inc. 1986.

[35] Erkarslan U, Oylumluoglu G, Coban MB, Öztürk E, Kara H. Cyanide-bridged trinuclear MnIIIFeIII assembly: Crystal structure, magnetic and photoluminescence behavior. Inorganica Chim. Acta. $445,57-61$.

[36] Coban MB, Erkanslan U, Oylumluoglu G, Aygun M, Kara H. Hydrothermal synthesis, crystal structure and Photoluminescent properties; 3D Holmium(III) coordination polymer. Inorganica Chimica Acta 2016; 447: 87-91.

[37] Feng X, Feng YQ, Chen JJ, Ng SW, Wang LY, Guo JZ. Reticular three-dimensional 3d-4f frameworks constructed through substituted imidazole-dicarboxylate: syntheses, luminescence and magnetic properties study. Dalton Trans. 2014; 44: 804-816.

[38] Song XQ, Peng YQ, Cheng GQ, Wang XR, Liu PP, Xu WY. Substituted group-directed assembly of $\mathrm{Zn}$ (II) coordination complexes based on two new structural related pyrazolone based Salen ligands: Syntheses, structures and fluorescence properties. Inorganica Chim. Acta. 2015; 427: 13-21.

[39] Manjunatha MN, Dikundwar AG, Nagasundara, KR. Zn(II), Cd(II) and $\mathrm{Hg}$ (II) complexes with 1(p-methoxybenzyl)-2-( $p$-methoxyphenyl)benzimidazole: Syntheses, structures and luminescence. Polyhedron 2011; 30: 1299-1304. 
[40] Feng X, Liu L, Wang LY, Song HL, Shi ZQ, Wu XH, Ng SW. Lanthanide coordination polymers based on multi-donor ligand containing pyridine and phthalate moieties: Structures, luminescence and magnetic properties. Journal of Solid State Chemistry 2013; 206: 277-285.

[41] Feng X, Wang LY, Zhao JS, Wang JG, Weng NS, Liu B, Shi XG. Series of anion-directed lanthanide-rigid-flexible frameworks: syntheses, structures, luminescence and magnetic properties. Cryst Eng Comm, 2010; 12: 774-783.

[42] Carnall WT. The Absorption and Fluorescence Spectra of Rare Earth Ions in Solution. NorthHolland, Amsterdam, 1979.

[43] Oliveira CAF, Silva FF, Malvestiti I, Malta VRS, Dutra JDL, Costa Jr. NB, Freire RO, Alves Jr S. Synthesis, characterization, luminescent properties and theoretical study of two new coordination polymers containing lanthanide [Ce(III) or $\mathrm{Yb}(\mathrm{III})]$ and succinate ions. Journal of Molecular Structure 2013; 1041: 61-67.

[44] Wang P, Fan RG, Yang YL, Liu XR, Xiao P, Li XY, Hasi W, Cao WW. 1-D helical chain, 2-D layered network and 3-D porous lanthanide-organic frameworks based on multiple coordination sites of benzimidazole-5,6-dicarboxylic acid: synthesis, crystal structure, photoluminescence and thermal stability. Cryst Eng Comm, 2013; 15: 4489-4506.

\section{SUPPLEMENTARY MATERIAL}

Crystallographic data for the structural analysis have been deposited with the Cambridge Crystallographic Data Centre, CCDC No. 1486497 for complex 1 and 1486498 for complex 2. Copies of the data can be obtained free of charge from the Director, CCDC, 12 Union Road, Cambridge CB2 1EZ, UK (fax: +44-1223-336-033; e-mail: deposit@ccdc.cam.ac.uk or www: http://www.ccdc.cam.ac.uk). 